\title{
COMMUNICATION
}

Check for updates

Cite this: Chem. Commun., 2020, 56,11445

Received 6th July 2020,

Accepted 18th August 2020

DOI: $10.1039 / \mathrm{d} 0 \mathrm{cc} 04666 \mathrm{c}$

rsc.li/chemcomm

\section{Visible light-mediated Smiles rearrangements and annulations of non-activated aromatics $\dagger$}

\author{
Connor A. Lawson, (D)*ab Andrew P. Dominey, ${ }^{a}$ Glynn D. Williams (D) $\ddagger^{a}$ and \\ John A. Murphy (D) *b
}

\begin{abstract}
We report the first examples of radical cation Smiles rearrangements. A series of aryloxy alkylamines underwent spontaneous reaction, with the amino group displacing the ipso-alkoxy group through substitution, at ambient temperature and under photoactivation by visible light in the presence of an acridinium catalyst (5 mol\%). The study was extended to 3-(2-methoxyphenyl)propan1-amine derivatives, which lack an appropriate ipso leaving group. Here, efficient cyclisations resulted in displacement of the methoxy group and formation of tetrahydroquinolines.
\end{abstract}

Development of complementary synthetic methods for the preparation of arylated amines is of high importance, due to their widespread presence in pharmaceuticals, natural products and organic materials. Phenol derivatives have emerged as attractive starting materials due to their abundance, and the ability to derive them from renewable sources. ${ }^{1}$

Over the last decade, photoredox catalysis has become immensely popular, through its role in engaging in efficient and sustainable transformations. ${ }^{2,3}$ The exploitation of visible-light has seen a vast number of methodologies developed that are of great synthetic utility due to the mild conditions deployed to access highly reactive species. ${ }^{4} \mathrm{~A}$ rising interest in photochemistry has been seen from the pharmaceutical industry. ${ }^{5}$

Organic photoredox catalysts are growing in popularity due to the avoidance of expensive and toxic metals such as ruthenium and iridium. ${ }^{6}$ Acridinium salts are among the most popular of these. ${ }^{7}$ In 2017, Tay and Nicewicz described with great success the use of acridinium salts to catalyse the nucleophilic aromatic substitution $\left(\mathrm{S}_{\mathrm{N}} \mathrm{Ar}\right)$ of anisoles with $N$-heteroaromatic amines

\footnotetext{
${ }^{a}$ Chemical Development, GSK, Gunnels Wood Road, Stevenage, SG1 2NY, UK. E-mail: connor.x.lawson@gsk.com

${ }^{b}$ Department of Pure and Applied Chemistry, University of Strathclyde, 295 Cathedral Street, Glasgow, G1 1XL, UK. E-mail: john.murphy@strath.ac.uk $\dagger$ Electronic supplementary information (ESI) available: Detailed experimental procedures and characterisation data for new compounds. See DOI: 10.1039/ d0cc04666c

\# Current address: API Development, Aptuit (Oxford) Ltd, an Evotec Company, 111 Innovation Dr, Milton, Abingdon, OX14 4RZ, UK.
}

(Scheme 1a). ${ }^{8}$ Further expansion of photocatalysed $\mathrm{S}_{\mathrm{N}} \mathrm{Ar}$ of anisoles has been reported by the Nicewicz group. ${ }^{9,10}$

We proposed that these conditions could be adapted to allow mild and efficient intramolecular reactions. The Smiles rearrangement is an intramolecular $\mathrm{S}_{\mathrm{N}} \mathrm{Ar}$ reaction occurring at the ipso position in an aromatic system..$^{11}$ The Smiles rearrangement is an important tool in synthetic chemistry, as demonstrated by diverse advances described in the literature. ${ }^{12}$ Generally, Smiles rearrangements are often limited to electron-poor arenes. Examples of thermally driven Smiles rearrangements of nonactivated aromatic systems are sparse and typically require forcing conditions and harsh reagents over prolonged reaction times (Scheme 1b). ${ }^{13}$

Neutral radical versions of the Smiles rearrangement are also known and have been established by the groups of Speckamp and Motherwell. ${ }^{14}$ More recently developments by Nevado ${ }^{15}$

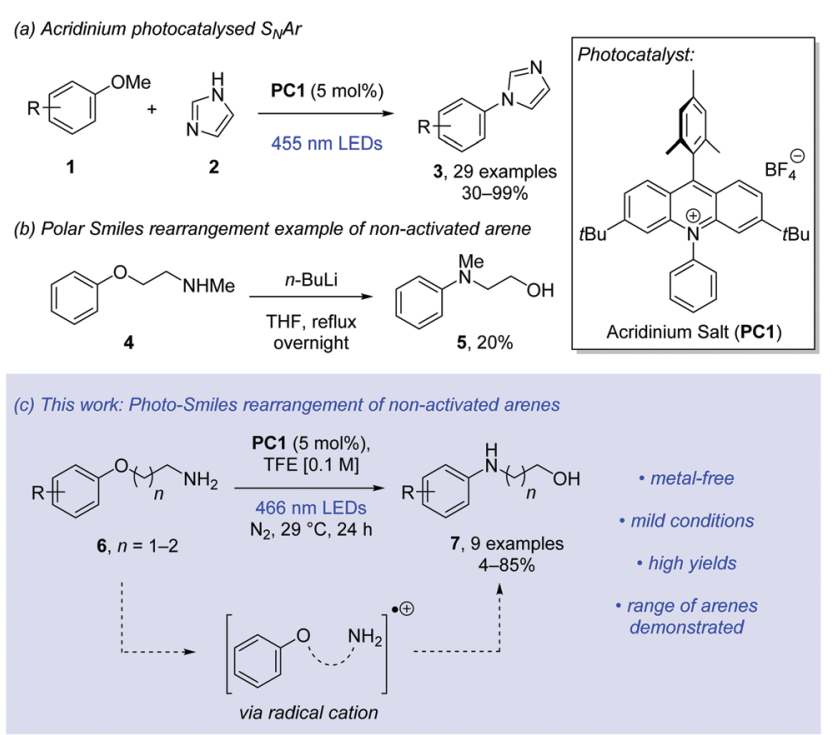

Scheme 1 Previous work and our approach to the Smiles rearrangement of non-activated arenes using photoredox catalysis. ${ }^{8-10,13 c}$ 
and Stephenson ${ }^{16}$ are part of an increasing torrent of radicalSmiles rearrangements reported in the literature, including photochemical and electrochemical methods. ${ }^{17}$

Inspired by recent developments in the Newman-Kwart rearrangement, where chemical, photochemical and electrochemical methods for single-electron oxidation enhanced reactivity, we proposed a radical cation approach to the Smiles rearrangement. ${ }^{18}$ We now show that a range of aryloxy alkylamines successfully undergo a mild and efficient photo-Smiles rearrangement using an acridinium salt as the organophotoredox catalyst (Scheme 1c).

To our knowledge, this approach yields the first examples of radical cation-promoted Smiles rearrangements. Our publication at this stage is prompted by the very recent report from the Nicewicz lab which details the use of primary alkylamine nucleophiles in intermolecular radical-cation accelerated nucleophilic aromatic substitutions. ${ }^{10}$

Our studies began with the evaluation of 2-phenoxyethan-1amine (6a). Pleasingly, the reaction of $\mathbf{6 a}(0.4 \mathrm{mmol})$ with 9-mesityl-3,6-di-tert-butyl-10-phenylacridinium tetrafluoroborate (PC1) $(5 \mathrm{~mol} \%)$ in a 1:1 mixture of 2,2,2-trifluoroethanol (TFE) and 1,2-dichloroethane (DCE) under visible light irradiation with a general purpose $40 \mathrm{~W}$ blue LED lamp (see ESI $\dagger$ for light source characterisation) in a nitrogen atmosphere for 24 hours at ambient temperature gave the rearranged product $7 \mathbf{a}$ in $87 \%$ solution yield (Table 1 , entry 1 ).

Employing TFE alone as solvent increased the observed solution yield to $92 \%$ (entry 2 ). In related systems, the importance of fluorinated alcohols has been linked to their ability to hydrogen bond key reaction intermediates. ${ }^{19}$ Changing to MeCN, a solvent with a lower toxicity burden than TFE, proved unsuccessful (entry 3,2\%). Moderate yields were observed when another highly fluorinated alcohol solvent, 1,1,1,3,3,3hexafluoro-2-propanol (HFIP), was employed (entry 4, 42\%). We also found that these reactions work equally as efficiently if DCE is replaced by $\alpha, \alpha, \alpha$-trifluorotoluene (TFT) (see ESI, $\dagger 86 \%$ ).

Based on photophysical and electrochemical properties, other commonly used organophotocatalysts were tested. 2,4,6Triphenylpyrylium tetrafluoroborate (TPT) (PC2) represents an example from an extremely powerful class of photo oxidants. ${ }^{20}$ However, a moderate solution yield of $29 \%$ was observed when PC2 was employed, possibly due to chemical instability (entry 5). ${ }^{21}$ Dicyanoanthracene (DCA) (PC3) offers an attractive catalyst alternative, owing to its structural simplicity and greater commercial availability. ${ }^{22}$ Under our conditions, DCA displayed a promising solution yield of $15 \%$, considering that it showed poor solubility in TFE (entry 6). Two other acridinium salts were also tested as photocatalysts (see ESI $\dagger$ ). Both showed good reactivity with slightly diminished yields over PC1, however, they have been reported in the literature as suffering from chemical instability ${ }^{3}$ and were pursued no further.

Once PC1 was established as the optimal catalyst, the loading was adjusted. Organocatalysis has been criticised for its inability to perform at low catalyst loadings. ${ }^{24}$ In our case, decreasing the catalyst loading to $1 \mathrm{~mol} \%$ (entry $7,92 \%$ ) had no effect on the reaction outcome. Moreover, no noticeable change
Table 1 Optimisation of the reaction conditions ${ }^{a}$

\begin{tabular}{|c|c|c|c|c|}
\hline & $6 \mathbf{a}$ & 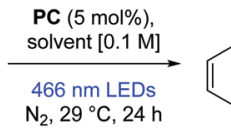 & $\mathrm{H}_{\mathrm{N}} \mathrm{OH}$ & \\
\hline & $\begin{array}{c}\mathrm{Ph} \\
\mathrm{PC1} \\
E_{\text {red }}^{*}=+2.15 \mathrm{~V} \mathrm{vs.} \mathrm{SCE} \\
\lambda_{\max }=413 \mathrm{~nm}\end{array}$ & $\begin{array}{c}\text { PC2 } \\
E_{\text {red }}^{*}=+2.55 \mathrm{~V} \text { vs. SCE } \\
\lambda_{\max }=415 \mathrm{~nm}\end{array}$ & $\begin{array}{r}\mathrm{CN} \\
\mathrm{PC3} \\
{E^{\mathrm{red}}}^{\star}=+1.99 \mathrm{~V} \\
\lambda_{\max }=422\end{array}$ & $\begin{array}{l}\text { IS. SCE } \\
\mathrm{Im}\end{array}$ \\
\hline Entry & Solvent [conc.] & $\begin{array}{l}\text { Photocatalyst PC } \\
\text { (loading) }\end{array}$ & Variations & $\begin{array}{c}\text { 7a yield }{ }^{b} \\
(\%)\end{array}$ \\
\hline 1 & $\begin{array}{c}\text { TFE : DCE }(1: 1) \\
{[0.1 \mathrm{M}]}\end{array}$ & PC1 (5 mol\%) & - & 87 \\
\hline 2 & TFE $[0.1 \mathrm{M}]$ & PC1 (5 mol\%) & - & 92 \\
\hline 3 & $\operatorname{MeCN}[0.1 \mathrm{M}]$ & PC1 (5 mol\%) & - & 2 \\
\hline 4 & $\operatorname{HFIP}[0.1 \mathrm{M}]$ & PC1 (5 mol\%) & - & 42 \\
\hline 5 & TFE $[0.1 \mathrm{M}]$ & PC1 (5 mol\%) & - & 29 \\
\hline $6^{c}$ & TFE $[0.1 \mathrm{M}]$ & PC1 (5 mol\%) & - & 15 \\
\hline 7 & $\mathrm{TFE}[0.1 \mathrm{M}]$ & PC1 (1 mol\%) & - & 92 \\
\hline 8 & $\mathrm{TFE}[0.1 \mathrm{M}]$ & PC1 (10 mol\%) & - & 90 \\
\hline 9 & TFE $[0.05 \mathrm{M}]$ & PC1 (5 mol $\%)$ & - & 96 \\
\hline 10 & $\mathrm{TFE}[0.2 \mathrm{M}]$ & PC1 (5 mol\%) & - & 82 \\
\hline 11 & $\operatorname{TFE}[0.1 \mathrm{M}]$ & - & - & Trace \\
\hline $12^{d}$ & $\mathrm{TFE}[0.1 \mathrm{M}]$ & PC1 (5 mol\%) & $\begin{array}{l}\text { Dark/ } \\
80^{\circ} \mathrm{C}\end{array}$ & 0 \\
\hline
\end{tabular}

${ }^{a}$ Unless otherwise stated, all reactions were conducted using $0.4 \mathrm{mmol}$ of $6 \mathrm{a}$ in degassed solvent $[0.1 \mathrm{M}]$ and irradiated with a Kessil lamp (40 W, A160WE Tuna Blue) for $24 \mathrm{~h} .{ }^{b}$ Yields determined by ${ }^{1} \mathrm{H}$ NMR analysis of the crude reaction mixtures using 1,3,5-trimethoxybenzene as an internal standard. ${ }^{c}$ Catalyst showed poor solubility in solvent. ${ }^{d}$ Reaction run at $80{ }^{\circ} \mathrm{C}$. $\mathrm{DCE}=1,2$-dichloroethane; $\mathrm{TFE}=2,2,2$-trifluoroethanol; HFIP $=1,1,1,3,3,3$-hexafluoro-2-propanol. Catalyst photophysical and electrochemical properties reported in literature.,

in yield was observed when catalyst loading was increased to $10 \mathrm{~mol} \%$ (entry $8,90 \%$ ). Dilution of the reaction mixture to $0.05 \mathrm{M}$ showed an improved solution yield (96\%) (entry $9 v s$. entry 2) and conversely, concentrating the reaction to $0.2 \mathrm{M}$ showed a drop in solution yield (entry 10, 82\%). For convenience, $0.1 \mathrm{M}$ was selected as the reaction concentration on this scale for further studies. Control reactions indicated the importance both catalyst and light had on the success of the transformation. In the absence of catalyst, trace amounts of product were observed (entry 11). Heating the reaction mixture to reflux in the dark with catalyst showed no product formation (entry 12).

Following screening, a range of arenes was subjected to the optimum conditions and the reaction products were subsequently isolated (Scheme 2). The product $7 \mathbf{a}$ derived from substrate 6a was isolated in $85 \%$ yield $\left({ }^{1} \mathrm{H}\right.$ NMR yield was 92\%). para-Alkyl substrates (6b-6d) were successfully rearranged and products isolated respectively in $63 \%, 73 \%$ and $80 \%$ yield. The success of isopropyl (6c) and tert-butyl (6d) substrates indicated that sterically bulky groups around the arene impacted little on the excited acridinium's ability for single electron transfer (see ESI $\dagger$ for further discussion). A single rearranged product $(7 \mathbf{e})$ was formed in good yield $(74 \%)$ when ortho-methoxy derivative (6e) was subjected to the reaction conditions. No competing cyclised product was observed as would 


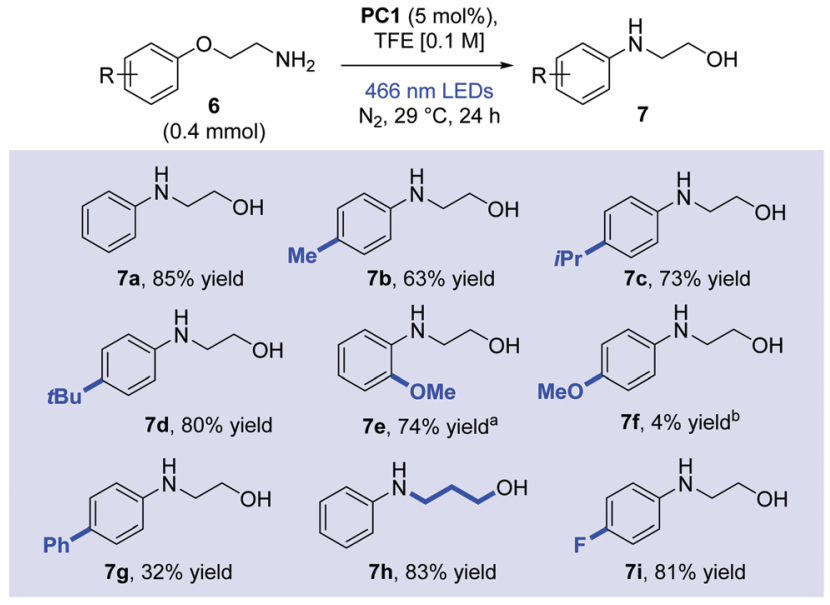

Scheme 2 Smiles rearrangement of primary amines. Yields reported as isolated yields following column chromatography. ${ }^{a}$ Reaction run in TFE: DCE (1:1) with $0.3 \mathrm{mmol}$ of substrate. ${ }^{b}$ Irradiated for $65 \mathrm{~h}$. DCE $=1,2-$ dichloroethane; TFE = 2,2,2-trifluoroethanol.

arise from displacement of the ortho-methoxy group, illustrating the faster kinetics of the ipso-substitution. To answer the question whether ortho-substitution would be possible in the absence of a Smiles rearrangement, we prepared and tested appropriate substrates (see below). Surprisingly, para-methoxy substrate (6f) showed poor conversion to product ( $4 \%$ isolated after $65 \mathrm{~h}$ irradiation), with unreacted starting material accounting for the remainder of the mass balance (see ESI $\dagger$ ). Biphenyl derivative $(\mathbf{6 g})$ gave a moderate yield of the desired Smiles product $7 \mathbf{g}(32 \%)$. Propylene-linked substituent (6h) was smoothly rearranged to the Smiles product ( $7 \mathbf{h})$ in $83 \%$ yield, progressing via a 6 -membered cyclic transtion state. The rearrangement also occurred with an electron-withdrawing fluoro present (6i) in excellent yield (81\%). However, a nitro-containing substituent $(\mathbf{6 j}$, see ESI $\dagger$ ) showed no reactivity under our conditions.

We note in the current results of Nicewicz and Venditto that secondary amines were not successful in intermolecular $\mathrm{S}_{\mathrm{N}} \mathrm{Ar}$ reactions. ${ }^{10}$ Our preliminary investigations into the Smiles rearrangement of secondary amines are noteworthy, showing modest initial success in converting challenging substrate (8) to product (9) and demethylated product (7a) (Scheme 3). It is likely that $7 \mathbf{a}$ arose from oxidative demethylation of $\mathbf{9 .}{ }^{6}$

Encouraged by the results of the ipso-substitutions seen above, we now moved to explore ortho-substitutions (Scheme 4). 3-(2Methoxyphenyl)propan-1-amine (10a) was prepared and was successfully cyclised to form tetrahydroquinoline (11a) in a good yield

$$
\text { (0.4 mmol) }
$$

Scheme 3 Smiles rearrangement of secondary amines. Yields reported as isolated yields following column chromatography. Unreacted starting material accounted for the remainder of the mass balance. TFE $=2,2,2-$ trifluoroethanol.

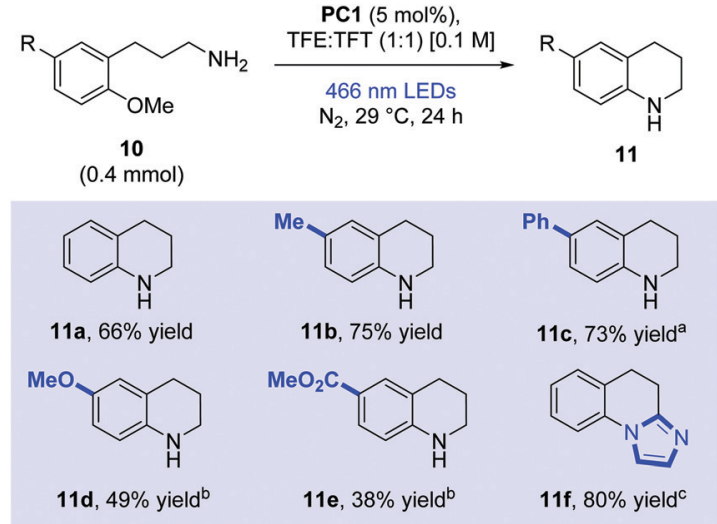

Scheme 4 Cyclisation of primary amines. Yields reported as isolated yields following column chromatography. ${ }^{a}$ Irradiated for $72 \mathrm{~h}$. ${ }^{\text {II }}$ rradiated for $40 \mathrm{~h}$. 'Reaction run in TFE: DCE (1:1). DCE = 1,2-dichloroethane; TFE = 2,2,2-trifluoroethanol; TFT $=\alpha, \alpha, \alpha$-trifluorotoluene.

(66\%). Tolyl (10b) and biphenyl (10c) derivatives were also cyclised in very good yields to provide the corresponding tetrahydroquinoline derivatives ( $75 \%$ and $73 \%$ respectively). Electron-rich dimethoxy derivative (10d) also cyclised well following prolonged irradiation times (49\%). Finally, electron-poor carbomethoxy derivative (10e) afforded desired product 11e in moderate yield (38\%). Synthetic applicability was extended to a medicinally relevant core with the efficient preparation of antibacterial imidazo[1,2-a]quinoline $\mathbf{1 1 f}(80 \%){ }^{25}$

Anisole derivatives $(c a .+1.8 \mathrm{~V}$ vs. SCE) and primary alkylamines ( +1.5 to $+1.6 \mathrm{~V} v s$. SCE) typically exhibit low oxidation potentials. ${ }^{26}$ Therefore, it is possible under the conditions employed (PC1, $E_{\text {red }^{*}}=+2.15 \mathrm{~V}$ vs. SCE) that the substrates undergo single electron oxidation at the amine or the arene. ${ }^{8}$ In closely related systems, mechanistic probing has suggested arene radical cations are key intermediates. ${ }^{8-10}$ However, other photoredox transformations involving alkylamines have been proposed to progress via amine radical cation pathways. ${ }^{27}$ Our proposed mechanism is shown below (Scheme 5). Visible light excitation of the ground-state acridinium salt (PC1) to an excited state (PC1a) enables the oxidation of phenoxyalkylamine (6a) to an arene radical cation (6aa). The tethered primary amine subsequently adds to the ipso-position, giving rise to Meisenheimer complex (6ab). Proton transfer and reduction by the acridinyl radical (PC1b) lead to the Smiles rearrangement product (7a) and regeneration of the ground state catalyst (PC1).

In conclusion, a range of primary aryloxylamines has been successfully reacted in a novel radical cation promoted photoSmiles reaction using an acridinium salt as an organophotocatalyst. The use of a single electron oxidant has enabled efficient Smiles rearrangements of electron-rich aromatics, that are typically inert and unreactive in this manner in the ground state, leading to substituted anilines via radical cation intermediates. Whereas these reactions show success in ipso rearrangement, ortho cyclisations of appropriate substrates to afford tetrahydroquinolines are also reported. We are currently extending these studies. 


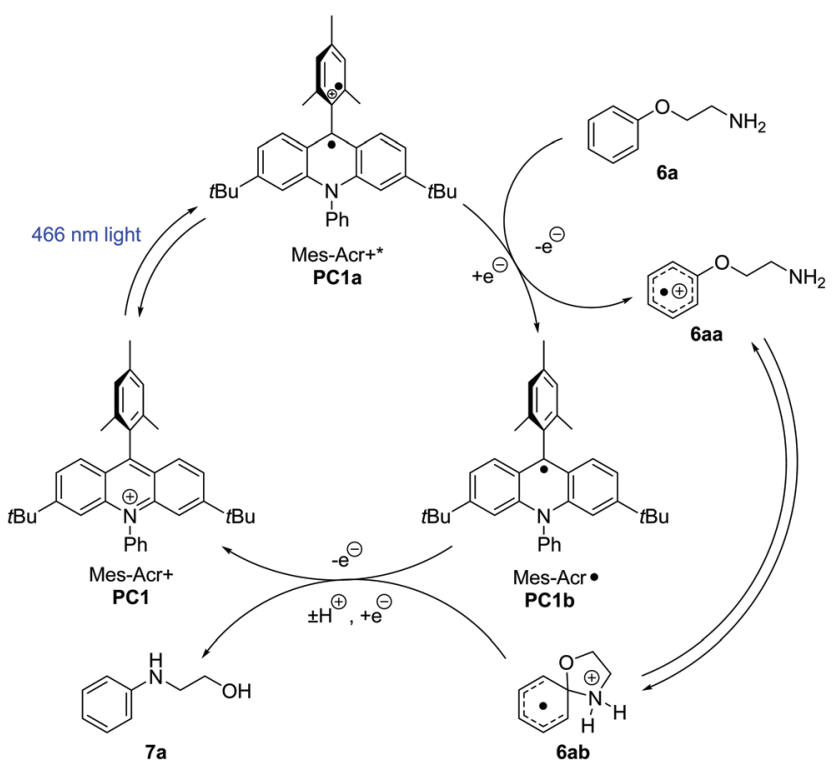

Scheme 5 Proposed Smiles rearrangement mechanism (adapted from Tay and Nicewicz). ${ }^{8}$

C. A. L. is grateful to GlaxoSmithKline for funding and chemical resources. We thank the EPSRC for funding via Prosperity Partnership EP/S035990/1.

\section{Conflicts of interest}

There are no conflicts to declare.

\section{Notes and references}

1 C. Li, X. Zhao, A. Wang, G. W. Huber and T. Zhang, Chem. Rev., 2015, 115, 11559; B. M. Upton and A. M. Kasko, Chem. Rev., 2016, 116, 2275.

2 G. E. M. Crisenza and P. Melchiorre, Nat. Commun., 2020, 11, 803.

3 N. A. Romero, K. A. Margrey, N. E. Tay and D. A. Nicewicz, Science, 2015, 349, 1326.

4 J. J. Douglas, M. J. Sevrin and C. R. J. Stephenson, Org. Process Res. Dev., 2016, 20, 1134; L. Marzo, S. K. Pagire, O. Reiser and B. König, Angew. Chem., Int. Ed., 2018, 57, 10034; M. K. Bogdos, E. Pinard and J. A. Murphy, Beilstein J. Org. Chem., 2018, 14, 2035.

5 H. E. Bonfield, K. Mercer, A. Diaz-Rodriguez, G. C. Cook, B. S. J. McKay, P. Slade, G. M. Taylor, W. X. Ooi, J. D. Williams, J. P. M. Roberts, J. A. Murphy, L. Schmermund, W. Kroutil, T. Mielke, J. Cartwright, G. Grogan and L. J. Edwards, ChemPhotoChem, 2020, 4, 45; H. E. Bonfield, T. Knauber, F. Lévesque, E. G. Moschetta, F. Susanne and L. J. Edwards, Nat. Commun., 2020, 11, 804.

6 N. A. Romero and D. A. Nicewicz, Chem. Rev., 2016, 116, 10075.

7 S. Fukuzumi, K. Ohkubo, T. Suenobu, K. Kato, M. Fujitsuka and O. Ito, J. Am. Chem. Soc., 2001, 123, 8459; A. Joshi-Pangu, F. Lévesque, H. G. Roth, S. F. Oliver, L.-C. Campeau, D. Nicewicz and D. A. DiRocco, J. Org. Chem., 2016, 81, 7244.

8 N. E. S. Tay and D. A. Nicewicz, J. Am. Chem. Soc., 2017, 139, 16100. 9 N. Holmberg-Douglas and D. A. Nicewicz, Org. Lett., 2019, 21, 7114.
10 N. J. Venditto and D. A. Nicewicz, Org. Lett., 2020, 22, 4817.

11 J. F. Bunnett and R. E. Zahler, Chem. Rev., 1951, 49, 273; W. E. Truce, E. M. Kreider and W. W. Brand, Org. React., 1970, 18, 99.

12 Z.-M. Chen, X.-M. Zhang and Y.-Q. Tu, Chem. Soc. Rev., 2015, 44, 5220; I. Allart-Simon, S. Gérard and J. Sapi, Molecules, 2016, 21, 878; C. M. Holden and M. F. Greaney, Chem. - Eur. J., 2017, 23, 8992; A. R. P. Henderson, J. R. Kosowan and T. E. Wood, Can. J. Chem., 2017, 95, 483; H. L. Barlow, P. T. G. Rabet, A. Durie, T. Evans and M. F. Greaney, Org. Lett., 2019, 21, 9033.

13 R. Bayles, M. C. Johnson, R. F. Maisey and R. W. Turner, Synthesis, 1977, 33; I. G. C. Coutts and M. R. Southcott, J. Chem. Soc., Perkin Trans. 1, 1990, 767; W. ten Hoeve, C. G. Kruse, J. M. Luteyn, J. R. G. Thiecke and H. Wynberg, J. Org. Chem., 1993, 58, 5101; J. J. Weidner, P. M. Weintraub, R. A. Schnettler and N. P. Peet, Tetrahedron, 1997, 53, 6303; C. Bonini, G. Cristiani, M. Funicello and L. Viggiani, Synth. Commun., 2006, 36, 1983.

14 R. Loven and W. N. Speckamp, Tetrahedron Lett., 1972, 13, 1567; J. J. Köhler and W. N. Speckamp, Tetrahedron Lett., 1977, 18, 631; W. B. Motherwell and A. M. K. Pennell, J. Chem. Soc., Chem. Commun., 1991, 877; M. L. E. N. da Mata, W. B. Motherwell and F. Ujjainwalla, Tetrahedron Lett., 1997, 38, 137.

15 W. Kong, M. Casimiro, E. Merino and C. Nevado, J. Am. Chem. Soc., 2013, 135, 14480; W. Kong, E. Merino and C. Nevado, Angew. Chem., Int. Ed., 2014, 53, 5078; N. Fuentes, W. Kong, L. Fernández-Sánchez, E. Merino and C. Nevado, J. Am. Chem. Soc., 2015, 137, 964.

16 J. J. Douglas, H. Albright, M. J. Sevrin, K. P. Cole and C. R. J. Stephenson, Angew. Chem., Int. Ed., 2015, 54, 14898; T. M. Monos, R. C. McAtee and C. R. J. Stephenson, Science, 2018, 361, 1369.

17 T. Zhou, F.-X. Luo, M.-Y. Yang and Z.-J. Shi, J. Am. Chem. Soc., 2015, 137, 14586; E. Brachet, L. Marzo, M. Selkti, B. König and P. Belmont, Chem. Sci., 2016, 7, 5002; J. C. Gonzalez-Gomez, N. P. Ramirez, T. Lana-Villarreal and P. Bonete, Org. Biomol. Chem., 2017, 15, 9680; D. M. Whalley, H. A. Duong and M. F. Greaney, Chem. - Eur. J., 2019, 25, 1927; S. W. Lardy, K. C. Luong and V. A. Schmidt, Chem. - Eur. J., 2019, 25, 15267; X. Chang, Q. Zhang and C. Guo, Org. Lett., 2019, 21, 10; Z.-H. Xia, L. Dai, Z.-H. Gao and S. Ye, Chem. Commun., 2020, 56, 1525; C. Liu, Q. Jiang, Y. Lin, Z. Fang and K. Guo, Org. Lett., 2020, 22, 795.

18 A. J. Perkowski, C. L. Cruz and D. A. Nicewicz, J. Am. Chem. Soc., 2015, 137, 15684; S. K. Pedersen, A. Ulfkjær, M. N. Newman, S. Yogarasa, A. U. Petersen, T. I. Sølling and M. Pittelkow, J. Org. Chem., 2018, 83, 12000; T. Broese, A. F. Roesel, A. Prudlik and R. Francke, Org. Lett., 2018, 20, 7483; S. Chiniforoush and C. J. Cramer, J. Org. Chem., 2019, 84, 2148.

19 L. Zhang, L. Liardet, J. Luo, D. Ren, M. Grätzel and X. Hu, Nat. Catal., 2019, 2, 366.

20 M. A. Miranda and H. Garcia, Chem. Rev., 1994, 94, 1063.

21 T. Zimmermann, G. W. Fischer and M. Reinhardt, Z. Chem., 1986, 26, 400 .

22 M. Freccero, M. Mella and A. Albini, Tetrahedron, 1994, 50, 2115.

23 R. Akaba, H. Sakuragi and K. Tokumaru, J. Chem. Soc., Perkin Trans. 2, 1991, 291; Y. Wang, O. Haze, J. P. Dinnocenzo, S. Farid, R. S. Farid and I. R. Gould, J. Org. Chem., 2007, 72, 6970; I. R. Gould, D. Ege, J. E. Moser and S. Farid, J. Am. Chem. Soc., 1990, 112, 4290.

24 D. W. C. MacMillan, Nature, 2008, 455, 304.

25 H. G. Bazin, L. S. Bess and M. T. Livesay, Org. Prep. Proced. Int., 2018, 50, 109.

26 J. L. Bourdelande, I. Gallardo and G. Guirado, J. Am. Chem. Soc., 2007, 129, 2817; H. G. Roth, N. A. Romero and D. A. Nicewicz, Synlett, 2016, 714.

27 K. A. Margrey, A. Levens and D. A. Nicewicz, Angew. Chem., Int. Ed., 2017, 56, 15644; A. J. Musacchio, B. C. Lainhart, X. Zhang, S. G. Naguib, T. C. Sherwood and R. R. Knowles, Science, 2017, 355,727 . 